\title{
Cross-Cultural Comparison between German, French and Dutch Consumer Preferences for Meat Substitutes
}

\author{
Ramona Weinrich ${ }^{1,2}$ (D) \\ 1 Management in Agribusiness, Department of Agricultural Economics and Rural Development, University of \\ Goettingen, 37073 Goettingen, Germany; ramona.weinrich@agr.uni-goettingen.de; Tel.: +49-551-39-19534 \\ 2 Centre of Biodiversity and sustainable Land Use, University of Goettingen, 37073 Goettingen, Germany
}

Received: 27 April 2018; Accepted: 29 May 2018; Published: 31 May 2018

\begin{abstract}
Sustainability is becoming an increasingly important consideration for consumers when purchasing food. As meat production has a significant impact on the environment, meat substitutes are becoming more and more popular in Europe. However, consumers who regularly buy meat substitutes are still the exception. Although there are some initial results indicating why this proportion is still low, most research has been concentrated in the Netherlands. This paper aims to compare reasons for consuming or not consuming meat substitutes in three European countries-Germany, the Netherlands and France. As very little is known about the underlying reasons, an explorative approach was chosen. Focus group discussions were carried out in all three countries, six altogether. The results show that all participants can enumerate meat substitutes. The main reason for not consuming meat substitutes is the taste of meat. Further, eating habits seem to be fixed and convenience might also be an impediment to reducing meat consumption in favour of meat substitutes, as is confusion regarding healthy eating.
\end{abstract}

Keywords: meat substitutes; sustainability; focus group discussions; cross-cultural comparisons; consumer preferences

\section{Introduction}

Meat substitutes are playing an increasingly important role in the sustainability debate in Western societies. Although in developing countries the demand for meat is still increasing, in some Western countries like Germany, France and Switzerland, the demand for meat has stagnated or is even slightly decreasing [1,2]. These tendencies can also be found in predictions of future dietary patterns. Recent consumer research shows that in 15 years' time, meat and dairy consumption will most likely have decreased in several consumer segments [3].

Sustainability aspects of meat consumption are manifold and typically subdivided into three dimensions [4-6]. However, in more recent approaches, sustainability is not only represented in three dimensions, but also in a fourth one [7]. The four pillars are described below.

Firstly, consumer motivation can be ecological as meat consumption has a negative impact on the environment [8-14]. However, it might be that consumers are not aware of this fact [15]. Secondly, from a social point of view, modern intensive livestock production is increasingly less accepted in Europe [16,17]. Especially in western European countries such as Germany, the Netherlands and France, where livestock density is relatively high, animal welfare considerations are discussed intensively (ibid.). Thirdly, agricultural economics; local, small-scale farms are disappearing and there is a constant price battle over food and especially meat amongst large retailers, so that meat is available at advantageous prices [18]. Fourthly, although a moderate red meat consumption might have a 
protective role for cancer prevention [19], high meat consumption is suspected of having negative impacts on human health [20-22]. The already high consumption levels of energy-rich foods continue to increase, including that of meat, milk and other dairy products [23]. Consequently, the consumption of monosaccharides and saturated fat is increasing (ibid.). However, the total fat consumption is supposed not to be related to higher mortality [24], whereas a high consumption of saturated fat increases the risk for higher mortality [25]. A partially vegetarian diet, e.g., one or two meat-free meals per week, would be an advantageous nutritional strategy not only in environmental terms but also for more general sustainability and for health aspects [26].

However, despite the reasons mentioned above for reducing meat consumption in Western societies, the consumption of meat substitutes is still low. In Germany, in 2015 only $11 \%$ of consumers had bought a meat substitute [27] despite the increasing range of products. In $20116 \%$ of all product launches in the meat sector were meat substitutes, while in 2016 the figure was already 20\% [28]. Why are European consumers still resistant to buying meat substitutes? Although there have been initial publications on the reasons why consumers either avoid or buy meat substitutes [29-34], cross-cultural research comparing European countries is still missing. However, cross-cultural comparison is favourable as results can provide indicators for meat substitute producers on how to adapt meat substitutes to gain consumer acceptance. Thus, the focus of this article is a cross-cultural comparison of three European countries: Germany, the Netherlands and France in an explorative approach. A society's openness to food innovations is crucial in determining whether novel food products are adapted or not. For this reason, the decision was made to compare these three western European countries as they differ in their degree of openness to innovation. The International Institute for Management Development (IMD) [35] ranks the Netherlands at position 11 in a comparison of the openness to innovation of 59 countries; Germany is ranked 32nd and France 58th. All three countries have high livestock densities so the ethical concerns and discussions of intensive livestock farming mentioned above are very relevant [16]. Furthermore, there are differences regarding consumption patterns. In Germany the naturalness of food plays an important role [36], while for French consumers food culture is characterised by enjoyment [37]. The food culture in France and the Netherlands also differs [38]: Dutch residents eat more overall and have smaller meals a day within shorter time periods (ibid.). In contrast, the French food culture encourages moderate social eating and minimises snacking habits [39]. Moreover, in France eating healthily is not seen as an end in itself, but the experience of eating (ibid.). These cultural differences are important in analysing whether or not meat substitutes will prevail in their respective food markets.

Although meat substitutes have an untapped potential to reduce the burden of intensive livestock farming on the environment [40-42], the focus of the literature to date has been on barriers to establishing meat substitutes in consumption patterns in the Netherlands. De Boer et al. [29] suggested not simply focusing recommendations on meat-free meals and meat reduction due to the cultural and structural aspects in meals; strategies should instead take a holistic view of the whole diet. Elzerman et al. [30] came to similar conclusions. They found that for the establishment of meat substitutes, sensory properties were not the most relevant consideration but rather the appropriateness of the meat substitute in meal combinations. Then again, in focus group discussions in the Netherlands, the meal context was not reported as an issue [31]. Instead, impediments such as a lack of information on the product package, high prices of meat substitutes and negative sensory aspects were mentioned (ibid.).

Further key impediments to consuming meat substitutes in the Netherlands and the UK were the unfamiliarity with meat substitutes and a lower sensory attractiveness compared to meat [32]. In order to promote meat substitutes ethical arguments for less meat consumption should, therefore, not necessarily be the focus of the communication [33].

To date however, no study has broached the issue of meat substitutes in a cross-cultural comparison in European countries. Thus, in an explorative approach, a total of six focus group 
interviews were carried out in Germany, The Netherlands and France. The aim was to detect variables that influence consumer to eat or avoid meat substitutes.

\section{Materials and Methods}

\subsection{Methodology}

Focus group interviews are a widely-used qualitative research tool in an explorative sense [43] and were used in this study as little is known about consumers' motives for choosing or not choosing meat substitutes in the three target countries. They are particularly suitable for obtaining an overview of the variation of opinions, ranges of values and of conflicts. The participants should be selected from the target group and while the sample can be small, it does not need to be representative. The group should consist of a minimum of four participants, but no more than nine in order to ensure that each participant is able to give his or her opinion [44]. Further, focus group interviews are appropriate for cross-cultural comparisons [45].

\subsection{Study Design}

Six focus group discussions were conducted; two in Germany (Göttingen), two in France (Reims) and two in the Netherlands (Amsterdam). As all focus groups should take place in the native language to ensure active participation, both the focus group interviews and the recruiting of the participants were carried out by experienced local market research institutes and their local consumer panels. There was a pre-screener to check age, gender, education level and net household income. Each session lasted $60 \mathrm{~min}$. There was a monetary incentive which was provided at the end of the focus group interviews. The six groups had a sample size of 43 (13 in Germany, 16 in France, 14 in the Netherlands). The youngest participant was 21 years old, the oldest 64 . There was a good mixture of gender, education levels and net household income within all six groups. A detailed description of the sample is in the Appendix A.

Before starting the focus group interviews, participants gave their informed consent for inclusion. They knew that they could revoke their approval at any time.

\subsection{Interview Structure and Procedure}

A semi-structured interview guide was prepared beforehand in line with the research objectives. The guide was translated into German, French and Dutch by native speakers. The focus group interview moderators in France and the Netherlands were briefed in written form and in a telephone conference.

After the moderator and co-moderator introduced themselves and asked if there were any questions, the audio and video recording was started. The research project was then briefly introduced. The groups were told that there were no right or wrong answers but rather that only personal opinions counted. Finally, participants were requested to follow common conversational etiquette, such as letting others have their say and only one person speaking at a time. Specific content-related stages followed.

Stage 1 included the participants introducing themselves. Each was asked to give his or her name, to say whether they had eaten meat substitutes before. If the answer was yes, then what kind of product it had been. After the introductions, a supplementary question was posed on what other kinds of meat substitutes the participants could think of. Suggestions were collected on a flip chart by the co-moderator.

In Stage 2 the participants were asked what the reasons might be why they substituted meat in meals or why not. In the next stage (Stage 3) the interviewees were requested to state impediments or advantages why they would not or would substitute meat in meals. Moreover, they were asked to state what they like or did not like about meat substitutes currently available on the market. A second supplementary question asked what price level would be acceptable and what would definitely be too expensive for a meat substitute. 
All pro and contra statements (Stages 2 and 3) were collected on a flipchart by the co-moderator. At the end of Stage 3, the participants individually ranked their three top reasons for and against meat substitutes in order to gain insights into the main impediments to establishing meat substitutes.

\subsection{Data Analysis}

The focus groups were recorded on audio and video. Transcriptions were made by native speakers. All transcripts were translated into English.

Codes were prepared following the discussion guide and the text was coded correspondingly. Two additional codes were included that were not part of the semi-structured interview guide but had arisen during the discussions. Transcripts were content-analysed using MAXQDA version 12, following the qualitative content analysis described by Schreier [46]. The process of the analysis is described in Figure 1. As the reliability of qualitative research is often criticised [44], content reliability was checked for intercoder reliability by the co-moderator. Both moderators coded the text. Discrepancies were found for between four and six codings per focus group. These discrepancies were discussed and consensus was found except for one coding. As the content could not be clarified, the passage was not coded.

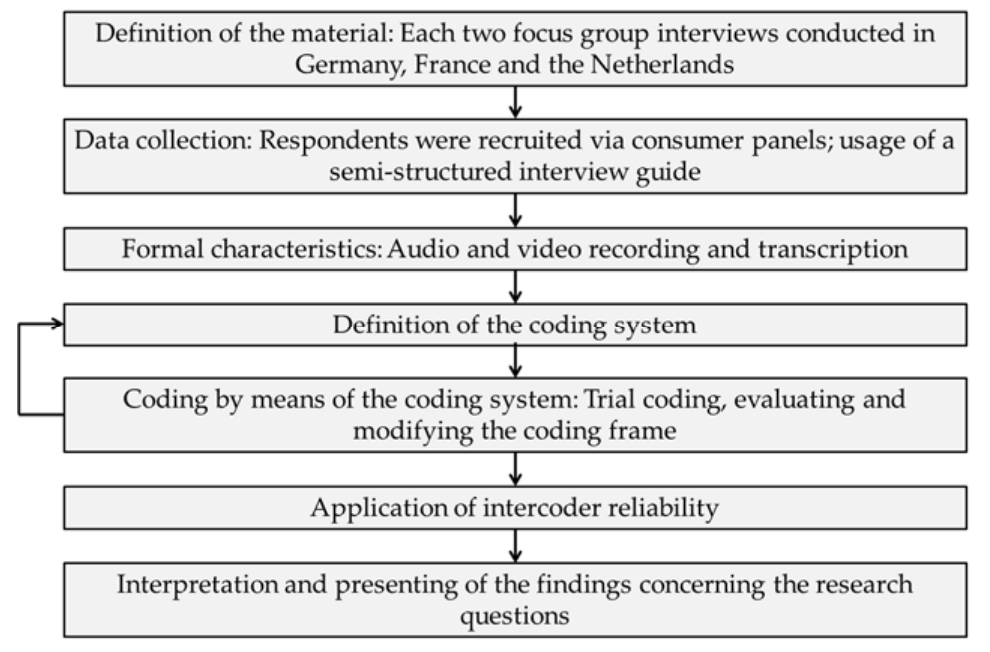

Figure 1. Process of the qualitative content analysis. Source: own presentation based on Schreier [46].

\section{Results and Discussion}

Primary themes of the results are emphasised and are organised thematically into three sections (food preferences and experiences with meat substitues; arguments for the uptake of meat substitutes; argument against the uptake of meat substitutes).

\subsection{Food Preferences and Experiences with Meat Substitutes}

Seven of the German participants paid little attention to origin, quality or quantity of meat consumption. Six participants paid attention to not eating too much meat and additionally watched out for origin and quality of the meat. One of these six participants did not eat meat and also tried to avoid other food of animal origin as far as possible; although she called herself a vegan she is flexible in social situations. Therefore she could rather be called a flexi-vegan. All German participants stated that they had tried at least one kind of vegetarian meal, although some participants were very sceptical about meat substitutes:

"It was probably 15 years ago when I tried something vegetarian, but I did not like it at all."

In the French focus groups, there was one vegetarian who also avoided eggs, thus also a kind of flexi-vegan. Three further participants said they only ate a little meat; between twice a week and once 
a month. All other French group members "ate everything". All the French participants had also tried meat alternatives, which for them included fish as an alternative. Three had tried a soy steak, but one participant added "that [it] didn't compare to meat".

The Dutch focus groups had fewer meat eaters than in the French groups. There were two vegetarians and three participants who could be characterised as flexitarians (consumers who eat meat seldom and choose it more conscientiously, e.g., in terms of animal welfare or quality). Of the remaining nine participants who all ate meat regularly, one participant had been a vegetarian for two years, and another had also tried to eat vegetarian but had not stuck with it:

\section{"[ ... ] I tried to remain so for a while, but I come from a family where we eat meat every day."}

A third participant amongst the meat eaters stated that he ate meat but with a bad feeling. As in the other two countries, the Dutch participants could also all enumerate at least one meat alternative. Remarkable for the Netherlands is that the participants stated several brands (Quorn, Tivall, Valess), which was not the case in the other countries. Table 1 gives a summary of the meat substitutes mentioned in the three countries.

Table 1. Stated meat substitutes by country.

\begin{tabular}{|c|c|c|}
\hline Germany & France & The Netherlands \\
\hline $\begin{array}{ll}\text { - } & \text { Tofu } \\
\text { - } & \text { (Diced) soy } \\
\text { - } & \text { Tofu in soy sauce } \\
\text { - } & \text { Vegetarian burger } \\
\text { - } & \text { (Green) spelt } \\
\text { - } & \text { Chickpeas } \\
\text { - } & \text { Falafel } \\
\text { - } & \text { Lupins } \\
\text { - } & \text { Seitan } \\
\text { - } & \text { Meat-free meatballs } \\
\text { - } & \text { Vegetarian bolognese sauce } \\
\text { - } & \text { Meat-free schnitzel } \\
\text { - } & \text { Vegetable schnitzel } \\
\text { - } & \text { Vegetables } \\
\text { - } & \text { Vegetarian mortadella }\end{array}$ & $\begin{array}{ll}\text { - } & \text { Tofu } \\
\text { - } & \text { Soy burger } \\
\text { - } & \text { Soy steak } \\
\text { - } & \text { Cegetarian steak } \\
\text { - } & \text { Quinoa } \\
\text { - } & \text { Fish } \\
\text { - } & \text { Crustaceans } \\
\text { - } & \text { Lussels } \\
\text { - } & \text { Eggils } \\
\text { - } & \text { Insects } \\
\text { - } & \text { Milk, yoghurt, curd } \\
\text { - } & \text { Flaky pastries filled with feta cheese } \\
\text { - } & \text { Vegese } \\
- & \text { In vitro meat from the lab } \\
- & \text { Fruits }\end{array}$ & $\begin{array}{ll}\text { - } & \text { Tofu } \\
\text { - } & \text { Soy } \\
\text { - } & \text { Vegetable burger } \\
\text { - } & \text { Different kinds of cereals } \\
\text { - } & \text { Beans } \\
\text { - } & \text { Fish }\end{array}$ \\
\hline
\end{tabular}

\subsection{Arguments for the Uptake of Meat Substitutes}

In the second stage of the focus group discussions, the participants were asked to specify reasons for substituting meat in meals. To begin with, ethical reasons were mentioned in the German focus groups: animal welfare, e.g., "[ ... ] poultry is totally overbred $[\ldots]$ " was a reason for consumers substituting meat, as well as working conditions in the meat sector. Also, in France, for the focus group discussion participants animal welfare was a reason to forego meat (e.g., "slaughterhouses, cruelty and mistreatment of animals"). Similarly, in the Netherlands one of the reasons that came up when talking about substituting meat was animal welfare:

"[ ... ] animal suffering. Before, when I was a kid, when we'd drive [on holiday] then you had these trucks coming by with pigs one on another, on their way to the slaughterhouse. And then three days without drinking water. Ohhh no ... I really thought that is not necessary."

The negative environmental impact of intensive livestock farming was also mentioned early on. In this context sustainability reasons were discussed, e.g., problems with the huge quantity of manure ("The important quantity of muck. The [excretions] of the animals [ .. ]"), which is currently an intensively discussed topic in the Netherlands, or the processing issue of the feed ("You could feed many more people with the soya grains than make meat out of it"). Also, in Germany the sustainability 
issue was discussed in depth, in terms of environmental impact, long transport routes that were mentioned repeatedly (which are of course also connected to animal welfare) as well as the legacy for future generations (sustainable use of resources):

"[ ... ] although I like meat [ ... ] that would be the only reason [ ... ] okay, at least I try to only eat meat once a week. For the environment and for my kids and my other descendants [ ... ]."

In terms of the consumption of meat itself, French consumers criticised poor meat quality and mistrust of the meat sector:

"Personally, I'm having a hard time believing there are enough animals [ ... ] to feed everyone. So I don't think all meat can be real meat. I don't really believe it."

Another participant added:

"That's what I mean, you have an amount of meat at the beginning, and then what they do with it ..."

In Germany, additional aspects were also quality-driven. Low meat quality was criticised as well:

"[ ... ] I can remember, when at home in the past, the schnitzel was put in the pan, it nearly did not shrink at all. [ ... ] and now I was watching the meat in the pan shrinking more and more. That was all water!"

However, in the Netherlands, not low meat quality but health reasons were discussed. They were variety in human diet as well as hormone and antibiotic residues in meat:

\section{"[ ... ] all the strange things that can be found in meat; hormones and antibiotics etc...."}

Furthermore, the participants were afraid of illnesses that could be passed on by farmed animals. In Germany, various health reasons were also debated passionately. The participants discussed meat being very fatty and thus a cause of several illnesses which could be summarised as metabolic syndrome. The consumers also thought that meat contained (accumulated) antibiotic residues, fertiliser residues and toxic residues. Apparently, consumers are not aware of the fact that there are strict legal provisions for residues in meat. This distorted perception of health hazards might be driven by media and non-governmental organisations. This can be supported by the fact that consumers assess particular risks more highly than experts do $[47,48]$. Similar health concerns were discussed in the French groups. One worry was that meat was often not fresh-which connected again with mistrust of the meat sector. As meat has a high calorie density, the participants in general doubted that high meat consumption was good for the body.

Interestingly, in the Netherlands, the bad taste of meat as well as general meat aversion were discussed in detail. Paradoxically, later in the discussion they emphasised the good taste of meat. Maybe this point here was due to social desirability. In this context the considerable improvement in the taste and texture of the latest meat substitutes was also mentioned, which enhances meat aversion and supports meat substitution:

"It is spiced as well so it [meat substitute] tasted the same [as meat]."

In Germany, meat texture was also mentioned in foregoing meat. Additionally, in the French participants' minds the preparation of meat substitutes is convenient and the price is not too high:

"It is not a high price compared to the price of meat"

"Meat can be expensive. So it could be cheaper to buy vegetarian."

Furthermore, the French participants agreed that the texture, taste, variety and appearance of meat substitutes have improved greatly ("Progress has been made though compared to the first tries"), which is also a positive aspect to substitute meat. As with the German focus groups, the French 
participants discussed positive aspects of substituting meat: there are no negative impacts on human health when foregoing meat. On the contrary, there is more variety in micronutrients. The Dutch participants found meat substitutes to be a good protein source and also agreed on the pleasant taste of meat substitutes.

After all possible reasons to avoid meat were discussed and collected on a flipchart, the participants were asked to rank their top three reasons for foregoing meat (A reason ranked number 1 resulted in three points, rank 2 in two points and rank 3 in one point). Table 2 gives an overview of what the consumers decided.

Table 2. Ranking reasons for foregoing meat.

\begin{tabular}{ccccccc}
\hline & \multicolumn{2}{c}{ Germany } & \multicolumn{2}{c}{ France } & \multicolumn{2}{c}{ The Netherlands } \\
\cline { 2 - 7 } & Reason & Points & Reason & Points & Reason & Points \\
\hline \multirow{3}{*}{$\begin{array}{c}\text { Priority } \\
\text { decreasing order }\end{array}$} & Animal welfare & 25 & Animal welfare & 19 & Health & 22 \\
\cline { 2 - 8 } & Health & 17 & Poor meat quality & 13 & Animal welfare & 20 \\
\cline { 2 - 8 } & $\begin{array}{c}\text { Environmental } \\
\text { impacts }\end{array}$ & 10 & Health & 10 & Sustainability & 12 \\
\hline
\end{tabular}

The ranking shows that in all three countries similar reasons were rated as important. In Germany and the Netherlands, animal welfare, human health and the environment or sustainability were the most crucial factors for avoiding eating too much meat.

However, in France besides animal welfare and health, meat quality was an important reason. This was also discussed in Germany but not ranked highly. In contrast, sustainability was less important for the French discussants. These statements from the focus group members support findings that French food culture is characterised by high quality and is connected with social interaction $[39,49]$. However, Hoek et al. [32,33] discussed for Dutch consumers that ethical and health arguments were not the only reasons why meat substitutes were bought. Nonetheless, meat quality might be underestimated in a group setting and socially desired aspects such as sustainability considerations might be overestimated. Further research should therefore quantify what marketing strategy is the most appropriate to promote meat substitutes, e.g., in a test supermarket or hypothetically with different information settings and a control and placebo group.

\subsection{Arguments Against the Uptake of Meat Substitutes}

In the third stage, counterarguments for consuming meat substitutes were required. Starting with the results of the German focus groups discussions, the consumers criticised the diverse choice of meat in comparison to the poor availability of meat-free products in out-of-home consumption.

"Also a lack of alternatives. [ ... ] if I am looking for a restaurant where such things are offered [meat alternatives], I do not make a find as fast as if I am just having a steak or a sausage, those I get around every corner."

"There is still an inadequate supply [of meat substitutes]."

In the same context, the participants also admitted that convenience is a reason to not eat meat substitutes, although many meat substitutes are processed and easy to prepare. It remains unclear if the participants had simply never bought any processed meat alternatives. This is closely connected to a lack of awareness in the preparation of meat-free meals. The participants stated that particularly during the barbecue season it was very convenient to have meat on the grill.

"There is our fast-moving society and our working lives, coming home in the evening and having a quick dinner. Exceedingly few cook for themselves. People rely on convenience food [ ... ] and it always contains meat." 
Thus, consuming meat is seen as a part of German society. Being invited to a party where there was not a meat-free alternative, a guest would not want to offend the host and so would eat the meat. In addition, participants stated that it was unpleasant to explain (repeatedly) why one did not eat meat (anymore).

The French participants also discussed social obligations: when invited to dinner and there being no vegetarian alternative then you just have to eat meat.

"Well when I go to people and there is meat, I am not difficult and I don't want to make a complete revolution so I get some. I find it quite good. I take a bite."

Cultural references were also mentioned in Germany and France, where the habit of eating meat is deeply imbedded. For the French participants, traditionally, a meal should consist of three components: meat, starch and vegetables. It was also concluded that meat contained essential nutrients.

"We are meat eaters so it is unnatural to not eat it at all. We can leave it from time to time but if you say we need more substitutes, no we are meat eaters."

"Because it is not a complete meal ..."

These findings for France are in line with findings by Rozin [39] and Rozin et al. [37] but the results emphasise that the social aspect can also be found in Germany. However, the social context is less relevant in the Netherlands, which is in accordance with de Castro et al. [38], who found that smaller meals throughout the day are dominating.

To complete this discussion issue, there were two additional codes that were not predefined: "wording of meat substitutes" and "renunciation of meat". The two codes are closely linked and, interestingly, were topics in all three countries. One German participant stated that he "does not really want to renounce meat but rather to eat vegetarian". This attitude of course is linked to the wording "meat substitute", which consumers in all three countries found difficult and inappropriate:

"Personally, I do not want to substitute anything, I just want to have the taste." (Germany)

"What you're looking to replace is the protein intake, there's no reason to call it a steak." (France)

"I am not necessarily looking for a meat substitute because I do not eat the traditional potatoes, vegetables and meat dish so then it is completely different." (Netherlands)

It therefore seems to be crucial to think about wordings that are inspired by meat, e.g., soy steak. That leads to another question; were members in the target groups looking for meat substitutes that look and taste like meat or might that even be an argument against buying those products, as consumers do not want to be reminded of meat? Further research is needed to clarify this question as recent Dutch research reported the need to make meat substitutes look like meat [30,31,33,50], e.g., via product tests in a sensory laboratory.

Taking the point further, the French participants agreed that meat is part of human nutrition. In this context they concluded that there was a desire to eat meat and not meat substitutes. These arguments support findings by de Boer et al. and Verain et al. $[29,51]$ that structural and cultural aspects as well as product categories are very important and a holistic approach to establishing meat substitutes is thus required, rather than simply focusing strongly on meat-free meals. Nevertheless, all French participants could enumerate meat substitutes, which in some cases they had previously eaten. This dichotomy has to remain unclear at this point. However, there was no such discussion in the Dutch focus groups. Again, this might be evidence that cultural food habits in terms of meat consumption have already changed in the Netherlands and, thus, meat-free meals are already more established.

A further impediment to consuming meat substitutes in France was availability: meat is easily available everywhere, whereas meat substitutes need to be searched for or bought in specialist shops. This can be verified by store checks carried out in France (own research). Why there is limited availability has to remain unclear. A reason for the scare availability might be that retailers are unsure about consumer demand. 
"No for me it is the fact that there are not enough substitutes to replace meat."

"Choice, the lack of diversity of available substitutes."

Further, Dutch participants cited a lack of knowledge on how to prepare meat-free meals:

"I never learnt to cook without meat. It's embarrassing but I have no idea of what I could prepare."

The same result was also found in a Dutch study [52].

Further aspects mentioned in the German groups were that the nutritional value of meat substitutes is lower and that the taste is rather artificial. They lacked micronutrients which were only contained in meat such as vitamin B12 and omega-3 fatty acids.

"If I can hardly get [vitamin] B12, I do not want to be forced to toss pills in all the time."

Another argument was the long, complex list of ingredients, which was characterised by additives which evoke uncertainty and an association with unnaturalness. In this context, the artificial taste of meat substitutes was mentioned:

"It tastes like they added artificial flavourings. It doesn't taste healthy, it doesn't taste natural, even without looking at the ingredients list."

The importance of naturalness for German consumers is in line with Kayser et al. [36]. Hence, meat substitutes should pursue the strategy of clean labelling, thus as few ingredients as possible.

Interestingly, in Germany and the Netherlands sustainability was a point of discussion concerning meat production, but not the production of meat substitutes. In contrast, the French participants thought that meat substitutes were not always sustainable:

"If you get a soy steak with genetically modified soy, or soy that's mass-produced in America, it defeats the purpose of trying to be sustainable. You need to know what you're eating."

However, it might be the case in Germany that consumers are not aware of the fact that many meat substitutes contain soy, as soy is strongly rejected by German consumers (own research, in preparation). The Dutch participants discussed additives as well as GMO (genetically modified organism) ingredients in meat-free products.

"When you read it carefully then you often have a lot of additives."

"And the fact that soya is modified..."

As a first step, in-depth interviews would be necessary to learn more about the attitudes towards soy as an ingredient in meat substitutes. Subsequently, a quantitative follow-up study can verify the qualitative results in a sample which is approximately representative of the respective population. If the result is that soy has low levels of acceptance, an alternative, e.g., lupins or microalgae, needs to be used.

The German participants also discussed price without being prompted by the moderator. The price of meat can be very low while the price of meat substitutes is comparatively high. Furthermore, the participants rated the price-quality ratio as unfavourable. The French found the price of meat-free products too high compared to the price of meat.

"Substitutes are not really cheaper than meat, and they should be, to encourage buying them."

To gain initial insights for a pricing strategy, acceptable price levels for the participants were requested by the moderators as a follow-up question. The German focus group participants came to the conclusion that the price of the meat substitute was not the dominating factor as long as the quality was appropriate. This might be due to social desirability, as price is a more decisive factor in comparison to the environmental impact of a product for example [53]. However, there was a maximum they were willing to pay; one participant for example suggested $€ 5$ as the maximum for 
a whole meal. The French discussants were more price-sensitive. They also paid more attention to quality. Nevertheless, the participants agreed they were not willing to pay more for a meat substitute than for a similar meat product. On the contrary, for them, a purchase incentive would be meat substitutes being cheaper than meat.

"The price should also be interesting enough for me to consider buying this instead of meat."

Furthermore, they directly compared the price per kilogram of meat and of meat alternatives. The Dutch participants discussed their willingness to pay from a more practical point of view. They also compared meat substitutes to meat prices. One and a half times the price of a comparable price for meat was accepted. The maximum willingness to pay was three times the price of meat.

As a conclusion, the German participants went on to discuss that the taste of meat was just too delicious to only follow a vegetarian diet. The same was discussed in France and the Netherlands.

In order to get a better overview of the mentioned reasons and motivations to not consume meat substitutes, the participants rated their top three arguments as in stage 2. Table 3 summarises the results.

Table 3. Ranking reasons not to substitute meat.

\begin{tabular}{ccccccc}
\hline & \multicolumn{2}{c}{ Germany } & \multicolumn{2}{c}{ France } & \multicolumn{2}{c}{ The Netherlands } \\
\cline { 2 - 8 } & Reason & Points & Reason & Points & Reason & Points \\
\hline \multirow{4}{*}{$\begin{array}{c}\text { Priority } \\
\text { decreasing order }\end{array}$} & Taste of meat & 20 & Taste of meat & 24 & Taste of meat & 25 \\
\cline { 2 - 8 } & Habit of eating meat & 13 & Micronutrients & 10 & Price & 10 \\
\cline { 2 - 8 } & Convenience & 11 & Health & 8 & "Something is missing" & 8 \\
\cline { 2 - 8 } & 11 & & $\begin{array}{c}\text { No trust in the labelling } \\
\text { of meat substitutes }\end{array}$ & 8 \\
\hline
\end{tabular}

In all three countries, the main reason for not consuming meat substitutes is the good taste of meat. Health arguments are also an issue. Further quantitative research is necessary to verify whether these issues are important for the majority of consumers in the respective countries.

\section{Conclusions}

The results of the focus group discussions in Germany, France and the Netherlands showed that consumers in all three countries could enumerate manifold substitutes for meat. However, traditional eating habits seem to be fixed, and convenience and a lack of skills as well as lack of availability and ideas in preparing meat-free meals seem to be major impediments to reducing meat consumption. It may be assumed that this is a major challenge in every country. However, the results suggest that cultural differences exist which may lead to the need for country-adjusted meat substitutes. There is some evidence that meat substitutes are already more established in the Netherlands than in Germany or France. However, most consumers in the focus groups like the taste of meat and this is the main reason for them to not substitute it. The realistic aim might thus be to substitute meat once or twice a week. However, these results have to be confirmed by a quantitative follow-up study.

Additionally, German consumers were more open-minded than French consumers to trying new meat substitutes. Nevertheless, participants in all three countries raised health concerns about meat substitutes. The discussions focused on additives and the artificialness of the products as well as concerns that the intake of essential vitamins or micronutrients might be insufficient. The paradox of the discussion of health (meat is healthy, too much meat is unhealthy, meat substitutes are healthy, but also unhealthy due to a lack of micronutrients) might lead to the conclusion that consumers are unsure about health aspects and that there is a lack of information. However, also these results have to be verified by a quantitative follow-up study.

The results presented in this paper are the first in this field offering a cross-cultural comparison in Europe and deliver important explorative insights into consumers' thinking and behaviour concerning 
meat substitutes. Still, all results refer to an explorative study which is a good starting point for finding relevant variables which can be used in a subsequent quantitative cross-cultural study. They can serve as a solid basis for future research.

Funding: This research was funded by the Lower Saxony Vorab by the Ministry of Education and Culture (MWK) grant number ZN 3041.

Acknowledgments: I gratefully thank Jana Rose for her support in preparing and conducting the focus groups and co-coding.

Conflicts of Interest: The author declares no conflict of interest. The founding sponsors had no role in the design of the study; in the collection, analyses, or interpretation of data; in the writing of the manuscript, and in the decision to publish the results.

\section{Appendix}

Table A1. Sample description.

\begin{tabular}{|c|c|c|c|c|}
\hline & \multicolumn{4}{|c|}{ Germany } \\
\hline & \multicolumn{2}{|l|}{ Focus Group 1} & \multicolumn{2}{|l|}{ Focus Group 2} \\
\hline & Description & $\begin{array}{c}\text { Frequency } \\
\text { (Except Age) }\end{array}$ & Description & $\begin{array}{c}\text { Frequency } \\
\text { (Except Age) }\end{array}$ \\
\hline Average age & & 38 & & 34 \\
\hline \multirow{2}{*}{ Gender } & Male & 3 & Male & 5 \\
\hline & Female & 5 & Female & 1 \\
\hline \multirow{3}{*}{ Education level } & Primary School & 1 & Primary School & 1 \\
\hline & Secondary School & 2 & Secondary School & 0 \\
\hline & A-Level & 5 & A-Level & 4 \\
\hline \multirow{7}{*}{$\begin{array}{l}\text { Net household } \\
\text { income }\end{array}$} & n.a. & 3 & n.a. & 0 \\
\hline & Less than $1500 €$ & 5 & Less than $1500 €$ & 3 \\
\hline & $1500-2500 €$ & 0 & $1500-2500 €$ & 0 \\
\hline & $2500 €$ or more & 0 & $2500 €$ or more & 2 \\
\hline & \multicolumn{4}{|c|}{ France } \\
\hline & \multicolumn{2}{|l|}{ Focus Group 1} & \multicolumn{2}{|l|}{ Focus Group 2} \\
\hline & Description & $\begin{array}{l}\text { Frequency } \\
\text { (Except Age) }\end{array}$ & Description & $\begin{array}{c}\text { Frequency } \\
\text { (Except age) }\end{array}$ \\
\hline Average age & & 40 & & 34 \\
\hline \multirow[b]{2}{*}{ Gender } & Male & 5 & Male & 5 \\
\hline & Female & 3 & Female & 3 \\
\hline \multirow{3}{*}{ Education level } & No qualification (still at school) & 1 & No qualification (still at school) & 1 \\
\hline & Secondary School & 3 & Secondary School & 0 \\
\hline & A-Level & 4 & A-Level & 7 \\
\hline \multirow{7}{*}{$\begin{array}{l}\text { Net household } \\
\text { income }\end{array}$} & n.a. & 0 & n.a. & 0 \\
\hline & Less than $1500 €$ & 5 & Less than $1500 €$ & 2 \\
\hline & $1500-2500 €$ & 2 & $1500-2500 €$ & 2 \\
\hline & $2501 €$ or more & 1 & $2501 €$ or more & 4 \\
\hline & \multicolumn{4}{|c|}{ The Netherlands } \\
\hline & \multicolumn{2}{|l|}{ Focus Group 1} & \multicolumn{2}{|l|}{ Focus Group 2} \\
\hline & Description & $\begin{array}{l}\text { Frequency } \\
\text { (Except Age) }\end{array}$ & Description & $\begin{array}{c}\text { Frequency } \\
\text { (Except Age) }\end{array}$ \\
\hline Average age & & 40 & & 46 \\
\hline \multirow{2}{*}{ Gender } & Male & 2 & Male & 4 \\
\hline & Female & 5 & Female & 3 \\
\hline \multirow{3}{*}{ Education level } & Middle Pro & 2 & Middle Pro & 3 \\
\hline & Higher Pro & 4 & Higher Pro & 2 \\
\hline & University & 1 & University & 2 \\
\hline \multirow{4}{*}{$\begin{array}{l}\text { Net household } \\
\text { income }\end{array}$} & n.a. & 0 & n.a. & 0 \\
\hline & Less than $1500 €$ & 2 & Less than $1500 €$ & 4 \\
\hline & $1500-2500 €$ & 2 & $1500-2500 €$ & 0 \\
\hline & $2500 €$ or more & 3 & $2500 €$ or more & 3 \\
\hline
\end{tabular}




\section{References}

1. European Commission. Agricultural Outlook for the EU Agricultural Markets and Income 2017-2030; EU: Brussels, Belgium, 2017.

2. Food and Agriculture Organization (FAO). The State of Food and Agriculture; Livestock in the Balance: Rome, Italy, 2009; Available online: http:/ /www.fao.org/docrep/012/i0680e/i0680e.pdf (accessed on 2 February 2018).

3. Nestlé. Zukunftsstudie: Was Is(s)t Deutschland 2030? Deutscher Fachverlag GmbH: Frankfurt am Main, Germany, 2015.

4. Gibson, R.B. Beyond the pillars: Sustainability assessment as a framework for effective integration of social, economic and ecological considerations in significant decision-making. J. Environ. Assess. Policy Manag. 2006, 8, 259-280. [CrossRef]

5. Hunkeler, D.; Rebitzer, G. The Future of Life Cycle Assessment. Int. J. Life Cycle Assess. 2005, 10, 305-308. [CrossRef]

6. Opp, S.M.; Saunders, K.L. Pillar Talk: Local Sustainability Initiatives and Policies in the United States-Finding Evidence of the "Three E's". Economic Development, Environmental Protection, and Social Equity. Urban Aff. Rev. 2013, 49, 678-717. [CrossRef]

7. Macdiarmid, J.; Kyle, J.; Horgan, G.; Loe, J.; Fyfe, C.; Johnstone, A.; McNeill, G. Liverwell: A Balance of Healthy and Sustainable Food Choices; Rowett Institute of Nutrition and Health: Aberdeen, UK; World Wildlife Fund UK: Aberdeen, UK, 2011.

8. Hallström, E.; Carlsson-Kanyama, A.; Börjesson, P. Environmental impact of dietary change: A systematic review. J. Clean. Prod. 2015, 91,1-11. [CrossRef]

9. Hednus, F.; Wirsenius, S.; Johansson, D.J.A. The importance of reduced meat and dairy consumption for meeting stringent climate change targets. Clim. Chang. 2014, 124, 79-91. [CrossRef]

10. Mackenzie, S.G.; Leinonen, I.; Ferguson, N.; Kyriazakis, I. Can the environmental impact of pig systems be reduced by utilising co-products as feed? J. Clean. Prod. 2016, 15, 172-181. [CrossRef]

11. Nguyen, T.L.T.; Hermansen, J.E.; Mogensen, L. Environmental costs of meat production: The case of typical EU pork production. J. Clean. Prod. 2012, 28, 168-176. [CrossRef]

12. Smil, V. Worldwide transformation of diets, burdens of meat production and opportunities for novel food proteins. Enzyme Microb. Technol. 2002, 30, 305-311. [CrossRef]

13. Van Mierlo, K.; Rohmer, S.; Gerdessen, J.C. A model for composing meat replacers: Reducing the environmental impact of our food consumption pattern while retaining its nutritional value. J. Clean. Prod. 2017, 165, 930-950. [CrossRef]

14. Vinnari, M.; Tapio, P. Future images of meat consumption in 2030. Futures 2009, 41, 269-278. [CrossRef]

15. Macdiarmid, J.I.; Douglas, F.; Campbell, J. Eating like there's no tomorrow: Public awareness of the environmental impact of food and reluctance to eat less meat as part of a sustainable diet. Appetite 2016, 96, 487-493. [CrossRef] [PubMed]

16. European Commission. Attitudes of EU citizens towards animal welfare. In Special Eurobarometer 270/Wave 66.1; European Commission: Luxembourg, 2007.

17. Scientific Advisory Board on Agricultural Policy. Pathways to a Socially Accepted Livestock Husbandry in Germany; Executive Summary and Synthesis Report; Scientific Advisory Board on Agricultural Policy: Berlin, Germany, 2015.

18. Magdelaine, P.; Spiess, M.P.; Valceschini, E. Poultry meat consumption trends in Europe. Worlds Poult. Sci. J. 2008, 64, 53-64. [CrossRef]

19. Oostindjer, M.; Alexander, J.; Amdam, G.V.; Egelandsdal, B. The role of red and processed meat in colorectal cancer development: A perspective. Meat Sci. 2014, 97, 583-596. [CrossRef] [PubMed]

20. Larsson, S.C.; Wolk, A. Meat consumption and risk of colorectal cancer: A meta-analysis of prospective studies. Int. J. Cancer 2006, 119, 2657-2664. [CrossRef] [PubMed]

21. Song, Y.; Manson, J.E.; Buring, J.E.; Liu, S. A Prospective Study of Red Meat Consumption and Type 2 Diabetes in Middle-Aged and Elderly Women. Diabetes Care 2004, 27, 2108-2115. [CrossRef] [PubMed]

22. Taylor, F.; Burley, V.; Greenwood, D.C.; Cade, J.E. Meat consumption and risk of breast cancer in the UK Women's Cohort Study. Br. J. Cancer 2007, 96, 1139-1146. [CrossRef] [PubMed] 
23. World Cancer Research Fund (WCRF). Food, Nutrition, Physical Activity and the Prevention of Cancer: A Global Perspective; World Cancer Research Fund/American Institute for Cancer Research: Washington, DC, USA, 2007; Available online: http:/ / www.aicr.org/assets/docs/pdf/reports/Second_Expert_Report.pdf (accessed on 2 February 2018).

24. Dehghan, M.; Mente, A.; Zhang, X.; Yusuf, S. Associations of fats and carbohydrate intake with cardiovascular disease and mortality in 18 countries from five continents (PURE): A prospective cohort study. Lancet 2017, 390, 2050-2062. [CrossRef]

25. Ricci, C.; Baumgartner, J.; Zec, M.; Kruger, H.S.; Smuts, C.M. Type of dietary fat intakes in relation to all-cause and cause-specific mortality in US adults: An iso-energetic substitution analysis from the American National Health and Nutrition Examination Survey linked to the US mortality registry. Br. J. Nutr. 2018, 119, 456-463. [CrossRef] [PubMed]

26. Helms, M. Food sustainability, food security and the environment. Br. Food. J. 2004, 106, 380-387. [CrossRef]

27. Mintel. Trend zu Fleischalternativen in Deutschland; Whitepaper; Mintel: London, UK, 2015.

28. Mintel. Verteilung der Anzahl der Produktlaunches von Fleischwaren und Fleischersatz in Deutschland in den Jahren 2011 bis 2016. 2016. Available online: https://de.statista.com/statistik/daten/studie/553273/ umfrage/fleischwaren-und-fleischersatz-produktlaunches-in-deutschland/ (accessed on 6 February 2018).

29. De Boer, J.; Schösler, H.; Aiking, H. 'Meatless days' or 'less but better'? Exploring strategies to adapt Western meat consumption to health and sustainability challenges. Appetite 2014, 76, 120-128. [CrossRef] [PubMed]

30. Elzerman, J.E.; Hoek, A.C.; van Bockel, M.A.J.S.; Luning, P.A. Consumer acceptance and appropriateness of meat substitutes in a meal context. Food Qual. Preference 2011, 22, 233-240. [CrossRef]

31. Elzerman, J.E.; van Bockel, M.A.J.S.; Luning, P.A. Exploring meat substitutes: Consumer experiences and contextual factors. Br. Food. J. 2013, 115, 700-710. [CrossRef]

32. Hoek, A.C.; Lunging, P.A.; Stafleu, A.; de Graaf, C. Food-related lifestyle and health attitudes of Dutch vegetarians, non-vegetarian consumers of meat substitutes, and meat consumers. Appetite 2004, 42, 265-272. [CrossRef] [PubMed]

33. Hoek, A.C.; Luning, P.A.; Weijzen, P.; Engels, W.; Kok, F.J.; de Graaf, C. Replacement of meat by meat substitutes. A survey on person- and product-related factors in consumer acceptance. Appetite 2011, 56, 662-673. [CrossRef] [PubMed]

34. Mullee, A.; Vermeire, L.; Vanaelst, B.; Mullie, P.; Deriemaeker, P.; Leenaert, T.; De Henauw, S.; Dunne, A.; Gunter, M.J.; Clarys, P.; et al. Vegetarianism and meat consumption: A comparison of attitudes and beliefs between vegetarian, semi-vegetarian, and omnivorous subjects in Belgium. Appetite 2017, 114, 299-305. [CrossRef] [PubMed]

35. International Institute for Management Development (IMD). World Competitiveness Yearbook 2011; IMD: Lausanne, Switzerland, 2011.

36. Kayser, M.; Böhm, J.; Spiller, A. Between Market and Morality-How is the German Agrifood Industry Perceived? Schriften der Gesellschaft für Wirtschafts-und Sozialwissenschaften des Landbaues e. V.; AgEcon Search, Waite Library, Department of Applied Economics, University of Minnesota: St. Paul, MN, USA, 2011; Volume 47, pp. 11-22.

37. Rozin, P.; Fischler, C.; Imada, S.; Sarubin, A.; Wrzesniewski, A. Attitudes to Food and the Role of Food in Life in the U.S.A., Japan, Flemish Belgium and France: Possible Implications for the Diet-Health Debate. Appetite 1999, 33, 163-180. [CrossRef] [PubMed]

38. De Castro, J.M.; Bellisle, F.; Feunekes, G.I.J.; Dalix, A.M.; de Graaf, C. Culture and meal patterns: A comparison of the food intake of free-living American, Dutch, and French students. Nutr. Res. 1997, 17, 807-829. [CrossRef]

39. Rozin, P. The meaning of food in our lives: A cross-cultural perspective on eating and well-being. J. Nutr. Educ. Behav. 2005, 37, 107-112. [CrossRef]

40. Aiking, H. Protein production: Planet, profit, plus people? Am. J. Clin. Nutr. 2014, 100, 483-489. [CrossRef] [PubMed]

41. FAO. Edible Insects: Future Prospects for Food and Feed Security. FAO Forestry Paper 171. 2013. Available online: http:/ / www.fao.org/docrep/018/i3253e/i3253e.pdf (accessed on 2 February 2018).

42. Veldkamp, T.; van Duinkerken, G.; van Huis, A.; Lakemond, C.M.M.; Ottevanger, E.; Bosch, G.; van Boekel, M.A.J.S. Insects as a Sustainable Feed Ingredient in Pig and Poultry Diets-A Feasibility Study; Rep. 638; Wageningen UR Livestock Research: Wageningen, The Netherlands, 2012. 
43. Lamnek, S. Gruppendiskussion: Theorie und Praxis; Beltz Verlag: Weinheim, Germany, 2005.

44. Casey, M.A.; Krueger, R.A. Focus group interviewing. In Measurement of Food Preferences; MacFie, H.J.J., Thomson, D.M.H., Eds.; Blackie Academic \& Professional: London, UK, 1994; pp. 77-96.

45. Perrea, T.; Grunert, K.G.; Krystallis, A. Consumer value perceptions of food products from emerging processing technologies: A cross-cultural exploration. Food. Qual. Preference 2015, 39, 95-108. [CrossRef]

46. Schreier, M. Qualitative content analysis. In Qualitative Data Analysis; Flick, U., Ed.; SAGE Publications: Thousand Oaks, CA, USA, 2014.

47. Siegrist, M.; Hübner, P.; Hartmann, C. Risk prioritization in the food domain using deliberative and survey methods: Differences between experts and laypeople. Risk Anal. 2018, 38, 504-524. [CrossRef] [PubMed]

48. Van Asselt, M.; Poortvliet, P.M.; Ekkel, E.D.; Kemp, B.; Stassen, E.N. Risk perceptions of public health and food safety hazards in poultry husbandry by citizens, poultry farmers and poultry veterinarians. Poult. Sci. 2018, 97, 607-619. [CrossRef] [PubMed]

49. Werle, C.O.C.; Trendel, O.; Ardito, G. Unhealthy food is not tastier for everybody: The "healthy = tasty" French intuition. Food. Qual. Preference 2013, 28, 116-121. [CrossRef]

50. Hoek, A.C.; van Bockel, M.A.J.S.; Voordouw, J.; Luning, P.A. Identification of new food alternatives: How do consumers categorize meat and meat substitutes? Food Qual. Preference 2011, 22, 371-383. [CrossRef]

51. Verain, M.C.D.; Sijtsema, S.J.; Dagevos, H.; Antonides, G. Attribute segmentation and communication effects on healthy and sustainable consumer diet intentions. Sustainability 2017, 9, 743. [CrossRef]

52. Schösler, H.; de Boer, J.; Boersema, J.J. Can we cut out the meat of the dish? Constructing consumer-oriented pathways towards meat substitution. Appetite 2012, 58, 39-47. [CrossRef] [PubMed]

53. Apostolidis, C.; McLeay, R. Should we stop meating like this? Reducing meat consumption through substitution. Food Policy 2016, 65, 74-89. [CrossRef]

(C) 2018 by the author. Licensee MDPI, Basel, Switzerland. This article is an open access article distributed under the terms and conditions of the Creative Commons Attribution (CC BY) license (http:/ / creativecommons.org/licenses/by/4.0/). 